\title{
El desastre en la literatura centroamericana contemporánea
}

The Disaster in Contemporary Central American Literature

Le désastre dans la littérature de l'Amérique centrale contemporaine

\section{Andrea Pezzè}

\section{OpenEdition}

\section{Journals}

Edición electrónica

URL: http://journals.openedition.org/rccs/6344

DOI: $10.4000 /$ rccs. 6344

ISSN: 2182-7435

Editor

Centro de Estudos Sociais da Universidade de Coimbra

Edición impresa

Fecha de publicación: 1 septiembre 2016

Paginación: 3-18

ISSN: 0254-1106

\section{Referencia electrónica}

Andrea Pezzè, «El desastre en la literatura centroamericana contemporánea », Revista Crítica de Ciências Sociais [En línea], 110 | 2016, Puesto en línea el 26 septiembre 2016, consultado el 30 abril 2019. URL : http://journals.openedition.org/rccs/6344; DOI : 10.4000/rccs.6344 


\title{
ANDREA PEZZÈ
}

\section{El desastre en la literatura centroamericana contemporánea*}

\begin{abstract}
Este artículo se propone analizar unos ejemplos de formulaciones literarias centroamericanas sobre los estragos ocasionados por las últimas guerras civiles. Para alcanzar tal objetivo, nos detendremos en tres escritores emblemáticos de la región: Horacio Castellanos Moya de El Salvador, Rodrigo Rey Rosa de Guatemala y Franz Galich entre Guatemala y Nicaragua, países que hoy en día están procurando trasladar sus experiencias traumáticas a un sistema lingüístico coherente. Nuestras reflexiones se apoyarán en el ensayo de Maurice Blachot L'écriture du désastre (1980), los estudios sobre la semántica de la memoria y las teorías sobre las culpas sociales para demostrar que la literatura de América Central -y también la hispanoamericana, en general- se encuentran ante una nueva encrucijada del estilo de representación de la realidad social.
\end{abstract}

Palabras clave: América Central; guerrilla; literatura; memoria; testimonio.

Palavras-chave: América Central; guerrilha; literatura; memória; testemunho.

\section{Introducción}

Una investigación sobre la literatura policial reciente en el panorama centroamericano se relaciona necesariamente con la catástrofe de las posguerras de los años noventa. Para elaborar una parte del complejo mapa de las problemáticas destacadas por las obras mesoamericanas de los últimos veinte años, nos parece útil referirnos al concepto de desastre y averiguar qué herramientas narratológicas, genéricas e ideológicas pueden surgir de su análisis. Este artículo se propone, por lo tanto, sondar ejemplos de formulaciones literarias centroamericanas sobre los estragos de las últimas guerras civiles. Para alcanzar dicho objetivo, se traerán a colación tres escritores centroamericanos: Horacio Castellanos Moya de El Salvador, Rodrigo Rey Rosa de Guatemala y Franz Galich, guatemalteco de nacimiento y nicaragüense de adopción.

* Este trabajo es cofinanciado por el Fundo Social Europeu, a través del Programa Operacional Potencial Humano, y por Fundos de la FCT - Fundação para a Ciência e a Tecnologia - en el marco de la Bolsa Posdoctoral SFRH/BPD/93975/2013. 
Los países que estos escritores representan, han vivido trayectorias sociales, políticas e históricas traumáticas y ahora recorren el difícil camino de transmitir la experiencia del duelo a través de un orden lingüístico coherente. En la década de los noventa, se asistió a un proceso de desmovilización de los beligerantes que todavía ha de evolucionar hacia una práctica eficaz en el ámbito político y social. O sea, los convenios de paz no han representado una pacificación de la vida cotidiana sino simple y llanamente la creación de otra tipología de conflicto. Por lo tanto, el desastre surge tanto en la reflexión sobre el pasado bélico como en el balance de la sociedad actual.

El texto de Maurice Blanchot L'écriture du désastre ofrece sugerencias interesantes para acercarse al discurso mismo sobre el concepto de catástrofe. Por consiguiente, construiremos pautas analíticas a través de algunas reflexiones que resultan de sus páginas.

El desastre no es sombrío, liberaría de todo si pudiese relacionarse con alguien, se le conocería en términos de lenguaje y al término de un lenguaje por una gaya ciencia. Pero el desastre es desconocido, el nombre desconocido que, dentro del propio pensamiento, se da a lo que nos disuade de ser pensado, alejándonos por la proximidad. Uno está solo para exponerse al pensamiento del desastre que deshace la soledad y rebasa cualquier pensamiento, en tanto afirmación intensa, silenciosa y desastrosa de lo exterior. (Blanchot, 1990: 12-13)

Podríamos hacer del desastre uno de los ámbitos privilegiados del lenguaje ya que se sitúa fuera del conocimiento inmediato y solo prevé un largo buceo en estructuras semánticas inusuales. El primer elemento que podemos articular del ensayo del filósofo francés es la idea de la búsqueda ineficaz, de la articulación lingüística imposible, próxima a la locura y al mal. En el ámbito hispánico e hispanoamericano, un ejemplo muy citado de este acercamiento asintótico a esta (des)organización del pensamiento es la escritura de Roberto Bolaño, autor que, dentro de su cosmopolitismo, tuvo cierta relación de cercanía geográfica y temporal con la Centroamérica que nos interesa (por su larga estadía en México en las décadas de los setenta y ochenta). Bolaño escribe, en palabras de Rodrigo Fresán, “desde la última frontera y al borde del abismo" (Fresán, 2008: 437). Siempre a punto de naufragar por mares tempestuosos (Bolognese, 2009), la literatura de Bolaño escudriña el desastre desde su orilla, ofreciéndonos una sensación desagradable de proximidad con algo que en nuestro cotidiano rechazamos. La locura en términos de eventualidad es una ejemplificación del desastre, básicamente por dos razones: primero, porque nuestra percepción de la enfermedad se asocia con el concepto de fin, de fracaso (de desastre); segundo, porque los lenguajes de la locura y del desastre son inefables, ininteligibles. 
Más allá de la dimensión individual del vacío lingüístico, en estas páginas vamos a tomar en cuenta la obra de tres escritores que se relacionan con traumas históricos, políticos y sociales. Por esta razón, esta primera referencia de Blanchot nos pone frente al arranque del trabajo de la escritura. La búsqueda de un lenguaje apto para devolver a la comunidad de lectores un (o múltiples) sentido(s). Pero este comienzo no es nada más que esto; a medida que vayamos desarrollando nuestras reflexiones, utilizaremos más enunciaciones de Blanchot como hitos de nuestro análisis.

Nos detendremos ahora en otra consideración introductoria sobre los procesos de absorción de un pasado traumático. En un estudio sobre la escritura pos-Auschwitz, António Sousa Ribeiro (Ribeiro, 2008: 11-12) trae a colación al filósofo y psiquiatra alemán Karl Jaspers quien especifica cuatro tipologías de culpa: las primeras tres tienen que ver directamente con los acontecimientos y son la culpa criminal, relacionada con los hechos delictivos, la culpa política, que depende de una decisión de mando, ${ }^{1}$ y la culpa moral, debida al conocimiento o al aval del acto nefasto (cuando esta culpa no es criminal). La cuarta, en cambio, tiene que ver con el concepto de colectivización de la culpa: es la culpa metafísica y "apunta a la responsabilidad que cada ser humano asume para sí relativamente a la violencia sobre cualquier ser humano" (ibidem: 12). Queremos usar esta última tipología ya que tiene que ver con los interrogantes que cada ciudadano se plantea acerca de su participación en la Historia y el papel social que quiere jugar en ella. Asimismo, la culpa metafísica se forja de la falta de sumisión de responsabilidades por parte de las autoridades y por manifestarse de forma aplastante una soberanía caracterizada por su estado de excepción -o sea fuera (o por encima)- del derecho (Agamben, 1995: 46).

Lejos de ofrecer una lectura psicoanalítica ${ }^{2}$ de este tipo de culpabilidad, trataremos de individuar dos actitudes posibles frente a ese vacío

\footnotetext{
${ }^{1}$ Por ejemplo, en el caso de la dictadura argentina del período 76-83, podríamos decir que la Ley de Obediencia Debida impidió la determinación de las culpas criminales mientras que la Ley de Punto Final trabó la posibilidad de determinar la culpa política.

${ }^{2}$ La narratividad del trauma es también un eje analítico muy interesante. Entre los numerosos estudios sobre testimonios y narrativización de las sociedades postraumáticas, tomamos una referencia de Pamela Ballinger que nos parece llamativa. Hablando de las formas de la memoria, reconoce "una transformación general desde una tipología de memoria más visual hacia otra más semántica. Tras esta transformación, la memorización se convierte en un proceso marcado por patrones lógicos, una sucesión de causas y efectos organizada en discursos sintácticos, más que en una representación visual del espacio" (1998: 101). El problema, que en estas páginas no logramos resolver completamente, depende de la duda de que las sociedades posbélicas centroamericanas puedan considerarse también postraumáticas. Como se verá, la actualidad de Guatemala, Nicaragua y El Salvador parecen forjadas sin solución de continuidad con los oprobios de la guerra. Por esta razón, no usamos la noción de trauma como algo que empieza a definirse a partir de un punto de la historia, sino como algo aún in itinere.
} 
lingüístico y hermenéutico: la primera, consiste en asumir la responsabilidad de denunciar, desde un punto de vista moral, político o ideológico, a los culpables de los crímenes; la segunda es una actitud parecida al estilo de Bolaño, y consiste en hundirse en el torbellino del sinsentido. El desarrollo de este artículo va a ofrecer un recorrido que empieza con una escritura comprometida y termina en una ficción paranoica, ${ }^{3}$ en la que el complot y la amenaza son elementos constituyentes de un laberinto de violencia (privada e institucional) de difícil interpretación. Esta última opción es detectable en los tres escritores y representa un recurso estético valioso y original y una toma de conciencia social y colectiva latinoamericana.

\section{Franz Galich}

Por lo que atañe a Franz Galich, iniciamos este rápido recorrido por su novela Huracán corazón del cielo, publicada en Managua en 1995. Podríamos pensar que el título alude al fenómeno atmosférico y por sí mismo a la catástrofe. Tras una lectura de la cosmogonía del Popul Vuh, nos percatamos que también es el génesis ya que la expresión en conjunto se refiere a la deidad del viento, tormenta y fuego que arrasó a los primeros hombres y luego se convirtió en renovación. En la novela, Huracán es un guerrillero guatemalteco, mítico y luminoso, que guía al pueblo hacia la liberación: "El silencio pobló la plaza, parecía desierta. El murmullo de miles de voces se fue filtrando entre las piedras milenarias. [...]. En la cima, Huracán sonreía listo para emprender el vuelo hacia el azul infinito [...]" (Galich, 1995: 168). Así termina la novela, en un anhelo de liberación que, en 1995, sonaba bastante tardío. Sin embargo, trataremos de considerar dicha visión retrospectivamente. No es una heroicidad propositiva -el Julio Antonio Mella de Paradiso (1967) de Lezama Lima: "un Dios en la luz, no vindicativo, no obscuro, no ctónico” (Lezama Lima, 2009: 287)-, sino analítica, dirigida hacia atrás en la voluntad de sistematizar lingüísticamente

\footnotetext{
${ }^{3}$ La de "ficción paranoica" es una definición de Ricardo Piglia: "Estos elementos sociales y formales, que están presentes en el género desde su origen, se exasperan hoy y dan lugar a esto que yo, de un modo totalmente hipotético, he llamado la ficción paranoica. [...] Uno es la idea de amenaza, el enemigo, los enemigos, el que persigue, los que persiguen, el complot, la conspiración, todo lo que podamos tejer alrededor de uno de los lados de esta conciencia paranoica, la expansión que supone esta idea de la amenaza como un dato de esa conciencia. El otro elemento importante en la definición de esta conciencia paranoica es el delirio interpretativo, es decir, la interpretación que trata de borrar el azar, considerar que no existe el azar, que todo obedece a una causa que puede estar oculta, que hay una suerte de mensaje cifrado que "me está dirigido" (Piglia, 1991: 5). La mirada de Sherlock Holmes, de Dupin, que mira el conjunto social como una red de signos que le están dirigidos a él para poder descifrar ese secreto a través de una suerte de mensaje que es necesario interpretar. "Por eso la novela policial está ligada al psicoanálisis y el psicoanálisis -como dice Octave Mannoni- no se sabe si es un saber sobre el delirio o es el delirio de un saber" (ibidem: 5).
} 
el desastre. La lucha en Guatemala se había ido consumiendo y los acuerdos de paz se firmaron en 1996. La novela de Galich, en su visión de los acontecimientos que se habían desarrollado desde la catástrofe del terremoto de 1976 hasta el final de la lucha armada, quiere poner orden en los sintagmas del desastre; distribuir las responsabilidades, absolver a los inocentes y librar a los oprimidos de la culpa metafísica. Por esta razón se configura como aide-mémoire de las relaciones de causa y efecto que llevaron a la guerra. Huracán corazón del cielo es una novela polifónica en la que Galich emplea muchos registros, desde el diario ${ }^{4}$ hasta el monólogo, pasando por la novela epistolar (donde las cartas de los guerrilleros se dirigen al palacio presidencial ubicado simbólicamente en Xibalbá, que en la religión Maya-Quiché es el infierno gobernado por deidades, estas sí, ctónicas). ${ }^{5}$ Dicha pluralidad presenta al lector el abanico de actores sociales involucrados en el conflicto: desde los revolucionarios o los indígenas representados en términos de grupos homogéneos, hasta la individualidad de Giordano, un profesor universitario, pasando por la crueldad del gobierno y del ejército.

Las dos estructuras literarias más importantes tienen que ver con la continua presencia de un mundo mítico indígena (visto en conjunto) insertado en una reivindicación de orden histórico occidental (constituida por individualidades como el Profesor Giordano). Es la voluntad de relacionar la cultura maya-quiché con la modernidad de la teoría marxista. "Era la reedición de la tragedia de 1524: en lugar de caballos, helicópteros y aviones. En lugar de mosquetes y arcabuces, ametralladoras y lanzacohetes" (Galich, 1995: 83). Un anhelo de realismo mágico que dirige esta novela hacia la etapa literaria latinoamericana más representativa (el conocido Boom), caracterizada por la voluntad de compromiso intelectual y reivindicación histórica.

\footnotetext{
${ }^{4}$ Más correctamente es el "Diario de un kaibil", donde se cuenta la educación para la violencia de los kaibiles, los operativos especiales del ejército guatemalteco en la lucha de contraguerrilla. En la novela, el diario quiere representar un documento (muy artefacto de la crueldad de los cuerpos especiales de los batallones centroamericanos. También en la novela El arma en el hombre (2001) de Horacio Castellanos Moya, aparece la crueldad kaibil. Como veremos más tarde, el manejo estético de los años de la guerra es diferente. En El arma en el hombre no rige la voluntad de sistematizar ideológicamente las culpas, sino la de mostrar el cinismo total de las sociedades centroamericanas: "Me explicó los métodos que utilizaron para ablandar a la población y limpiar de terroristas la zona: cada kaibil debía violar y destazar a una niña y luego beber su sangre, dijo. Cosas de indios" (Castellanos Moya, 2001: 41). Por mucho que pueda parecer extraño, aquí también tenemos una referencia al pasado cultural indígena. Sin embargo, dichas tradiciones resultan exacerbadas, por un lado, por la idealización de un pasado glorioso, y por otro, por un recrudecimiento continuo del lenguaje y de las prácticas sociales.

5 "Para burlar a los señores de Xibalbá, una raíz los recogerá y viajarán por la savia de la milpa hasta llegar a la mazorca que, al ser calentada por el sol, se desgranará y un cenzontle se los tragará y así llegarán hasta su destino, burlando todas las vigilancias que tienen los Señores de Xibalbá" (Galich, 1995: 60).
} 
Esta fe ideológica permite la verbalización del desastre y la distribución de las culpas. La biografía de su autor (nacido en Guatemala, fue un intelectual activo en el comienzo de la insurrección, se exilió en México y luego en Nicaragua donde apoyó la lucha sandinista), el tratamiento de los personajes y la técnica narrativa insertan Huracán corazón del cielo en la larga estela de novelas que se enfrentaron con el poder político desde un punto de vista ideológicamente centrado.

También en otra novela, entre las más importantes de Galich, es evidente la voluntad de transmitir al lector un mensaje positivo y de denunciar los oprobios sociales. Nos referimos a Tikal Futura (Memorias para un futuro incierto), obra de ciencia ficción, publicada póstumamente en 2012, en la que se presenta un futuro distópico. La historia cuenta la contraposición entre dos ciudades (Tikal, en maya-quiché, es la palabra que designa la ciudad), una de arriba y otra de abajo. La primera es el lugar de los burgueses asentados que explotan salvajemente a través de la contaminación, la esclavitud del trabajo y el control de la mente, a los habitantes de la segunda. De la misma forma que en muchas ficciones distópicas, existe un núcleo de rebeldes que no logra zafarse de los aparatos de control mental y que se organiza alrededor de la ideología de los grupos guerrilleros de la segunda mitad del siglo xx. Como en Huracán corazón del cielo, ${ }^{6}$ esta novela dialoga con el desastre y hasta le deja cierta ventaja. En la tradición de la ciencia ficción latinoamericana, ${ }^{7}$ Galich presenta un futuro provocado por lo que parece ser un desarrollo algebraico de la explotación, la violencia y la contaminación en el sur del mundo. Sin embargo, tal como hizo en Huracán..., dicha relación con el desastre es nombrable ya que se especifican las soluciones concretas -teóricas y prácticas- para el desastre mismo. Es decir, la lucha revolucionaria e ideologizada es señalada como solución eficaz.

\footnotetext{
${ }^{6}$ Los temas son muy parecidos entre ellos. El entramado de mitología indígena y resistencia guerrillera son las herramientas a través de las cuales se construye un texto de resistencia y, al mismo tiempo, de memoria. Más aún, podríamos hablar de hipertextos ya que cada referencia a los personajes y sus hazañas funciona como enlace para conectar al lector con la arqueología (o la enciclopedia) de la cultura latinoamericana: "'La oportunidad parece que se presenta después de tanto tiempo', pensó la abuela que escribiría en el Libro de los Consejos, como lo había denominado de manera críptica, en homenaje a otro supuesto texto sagrado desaparecido en las páginas del tiempo, pues el nombre anotado en la tapa [...] era: 'Memorias para un futuro incierto'”. Tikal Futura y la sabiduría de la abuela se nos presentan como escenario de la escritura en América Latina; o sea, a través de un texto que remite a otro precolombino y, al mismo tiempo, al comienzo de la tradición de la crónica y de la prosa en general en lengua española. En la misma página, la crónica de los acontecimientos se relaciona con el mito y con Huracán...: "¿Qué locura invadía la mente del Creador Corazón del Cielo para hacerme como me hizo?” (Galich, 2012: 225).

7 Para una idea de la difusión del género en América Central, se señala como referencia el número 23 de la revista Istmo. Revista virtual de estudios literarios y culturales centroamericanos de julio-diciembre de 2011.
} 
El desastre es una coyuntura presente desfavorable que no impide la posibilidad de acabar con él y de construir, gracias al compromiso de unos cuantos valientes (tema del "foquismo" guevariano), una sociedad más justa.

En la producción literaria de Franz Galich se encuentran ejemplos notablemente diferentes. Fallecido en 2007, antes de morir publica dos novelas -Managua Salsa City ;Devórame otra vez! (2000) y su continuación Y te diré quién eres (Mariposa traicionera) (2006)-, donde el mundo centroamericano es un lugar de acechos, contubernios, narcotráfico y contrabando de armas. Leídas en conjunto, las dos novelas ofrecen un recorrido por las hazañas del protagonista que se hunde (junto a la totalidad de la sociedad en que vive) en un torbellino de violencia espeluznante donde verdad, culpa y derecho son opciones simplemente arbitrarias e individuales. A pesar de su compromiso como intelectual, Galich no huye de la representación de Managua en términos de vacío: moral, ideológico (Pancho Rana era un militar sandinista que en la posguerra hace de la violencia su negocio) y social.

A las seis en punto de la tarde, Dios le quita el fuego a Managua y le deja la mano libre al Diablo. El reloj de Dios es de los buenos pues nunca le falla: todos los días, a la misma hora, baja un poco la brasa del calor [...] y entonces [...] empiezan a salir los diablos y las diablas. (Galich, 2000: 1)

Managua Salsa City e Y te diré quién eres recorren los males endémicos de muchos países del istmo, sin aparentemente detenerse en un juicio moral sobre las dinámicas de los acontecimientos ni el arbitrio de los personajes, insertándose dentro una tipología literaria que Beatriz Cortez define como cínica (2009).

A continuación, vamos a entrar en el análisis de dos escritores que hacen de la locura social y la imposibilidad de su racionalización un pilar fundamental de sus estéticas.

\section{Rodrigo Rey Rosa}

Una actitud lúcida frente a la posibilidad del desastre, es la de Rodrigo Rey Rosa. El volumen Imitación de Guatemala (2013) recoge las novelas breves del guatemalteco. Tres de ellas interesan para nuestro discurso: Que me maten si... (1996), El cojo bueno (1996) y Piedras encantadas (2001). ${ }^{8}$ El hilo conductor de las tres obras es la escasa importancia de la relación entre la reconstrucción de los hechos, el valor de la verdad y la justicia. Por razones

${ }_{8}^{8}$ Por abarcar un argumento más familiar que social, la novela Caballeriza (2006), cuarta de la colección, no se incluye en este trabajo. 
diferentes (coerción de un poder oculto o desinterés individual), la realidad es al mismo tiempo un conocimiento tan explícito como inútil que, al impedir una relación antagonista a la culpa criminal, no deja otra cosa que un resignado cinismo frente a la misma culpa metafísica. En las novelas, de hecho, la determinación de los culpables se da a través de un constructo lógico típico del policial pero, a diferencia de este, en las novelas de Rey Rosa el hallazgo ingenioso de la realidad de los hechos no es otra cosa que una circunstancia sin consecuencias.

Una primera tipología es la de Que me maten si... Un anciano escritor y periodista inglés trabaja también como espía para tratar de averiguar los crímenes de los militares contra los indígenas guatemaltecos. En una de sus misiones es detectado y enseguida desaparece. Una amiga guatemalteca, huida de su país por sentirse amenazada, decide volver para tratar de descubrir donde terminó su amigo. La investigación la lleva hasta una verdad que le es vedada por el complot que se le cierne encima y que ella (o el narrador) acata con resignación. Es el poder que impone -a través de la violencia cual imposición de unos enunciados- el conocimiento y que actúa sobre su articulación.

En cambio, El cojo bueno y Piedras encantadas se desarrollan dentro del conocimiento mismo del desastre. Para no resultar pedantes o repetitivos, traemos a colación solo la novela El cojo bueno. Aquí Juan Luis, el protagonista, es víctima de un secuestro. Por unas coincidencias casuales pero fehacientes, decide regresar de Marruecos -donde se mudó para olvidar la violencia padecida- para localizar a sus secuestradores, ya que uno de ellos, apodado La Coneja, le es conocido. Sin previo aviso, Juan Luis visita a su verdugo. Éste, alarmado, trata de esconderse en un lugar remoto. El problema reside en que Juan Luis no tiene ninguna intención de denunciarlo, únicamente quiere enfrentarse con el concepto de culpa. La articulación lingüística del desastre no produce reacción alguna por parte del protagonista, quien no hace otra cosa que escuchar el relato de su verdugo y hacer unas preguntas baladíes. Por un lado, tenemos la idea de la culpa; por otro, el desastre es la falta de acción tras su conocimiento.

El desastre, al quitarnos el refugio que es el pensamiento de la muerte, al disuadirnos del pensamiento de lo trágico o de lo catastrófico, al desinteresarnos de todo querer como de cualquier movimiento interior, tampoco nos permite jugar con esta pregunta: ¿Qué hiciste por el conocimiento del desastre? (Blanchot, 1990: 11)

Gracias a esta segunda opinión de Blanchot, podemos argüir una visión más completa del desastre. Tenemos entonces un movimiento, una ida 
hacia el conocimiento del desastre y, a continuación, la toma de conciencia de su inefabilidad. En Rey Rosa es evidente. Por ejemplo, el protagonista de El cojo bueno se mueve (literalmente, en el espacio que mide entre Marruecos y Guatemala) para conocer el desastre que marcó definitivamente su vida. Al llegar frente al narrador (uno de los secuestradores) de la historia de la catástrofe que sufrió, decide no articular de forma coherente las palabras del desastre que el otro podía ofrecerle. En Galich, en cambio, este movimiento hacia el vacío parece oscilatorio. A pesar de la voluntad constante de acercarse al conocimiento del desastre, una parte de su producción trata de racionalizar la catástrofe de la guerra (Huracán..., Tikal Futura), ofreciendo unas soluciones concretas; otra la reitera en un callejón sin salida que no brinda soluciones de continuidad al desmoronamiento (Managua..., Y te diré...).

Si el pasado es una catástrofe, el futuro es una jaula. La coyuntura de estos dos movimientos se realiza también en El material bumano (2009). La novela cuenta la investigación del narrador-protagonista sobre Benedicto Tun, primer criminólogo de Guatemala, creador del Gabinete de Investigación en 1922 y autor de un texto autobiográfico Memorias de labores de la Policía Nacional (1938). Aquí, nuevamente, el movimiento es concreto y literario. El narrador sale de su casa para visitar el Archivo del Gabinete; también es literario, ya que la novela ficcionaliza el proceso de construcción de un texto. Los tres géneros que se interconectan en la novela -metanarrativización de un proceso de creación literaria, biografía de Tun y ensayo- se traban en la imposibilidad de constituir un texto apto para ordenar los múltiples puntos de vista sobre el archivo del homo sacer (Agamben, 1995: 46 ss.) y del desastre social guatemalteco. Esto sucede porque el protagonista recibe unas amenazas por las cuales termina huyendo al extranjero. El desastre bajo la forma de complot se desdibuja en El material humano gracias a un juego intertextual: mientras trata de buscar elementos para escribir una biografía de Tun y una genealogía del control social en su país, el protagonista lee la biografía de Joseph Fouché -fundador de la policía secreta francesade Stefan Zweig. Frente a ese documento literario, nos damos cuenta de que es imposible escribir un itinerario del control científico de la vida de los guatemaltecos y también una novela que esclarezca la historia de las maniobras ocultas del Estado. El desastre, por lo tanto, se relaciona con el inevitable silenciarse del papel testimonial del intelectual. Es un acercamiento paulatino al borde del abismo; es decir, a esa condición de falta de racionalidad y orden lingüístico que es la gran tarea social del lenguaje. Nuevamente con Sousa Ribeiro vemos que: las cuestiones que quedan y quedarán abiertas [...] no son relativas, pues, al esclarecimiento de los sucesos ni a la simple interpretación histórica, sino a la memoria y a la posmemoria, es decir, a la 
relación con el pasado estructurada a partir de la implicación presente de subjetos concretos" (Ribeiro, 2008: 14). La memoria pugna siempre con el desastre: por un lado, la voluntad de reconstruir los hechos; por otro, la falta total de semántica. Por esto, podemos concluir que "[e]l desastre está del lado del olvido; el olvido sin memoria, el retraimiento inmóvil de lo que ha sido trazado [...]” (Blanchot, 1990: 11).

\section{Horacio Castellano Moya}

Horacio Castellanos Moya es quien en cambio se hunde en la locura lingüística del desastre. Este es el legado de una desaforada violencia estatal o ideológica que acarrea la imposibilidad de dimensiones interpretativas subjetivas: una serie de paranoicos organizan versiones distorsionadas de la relación con el poder y la realidad.

Antes de seguir tratando acerca de la literatura de Castellanos Moya, nos detendremos en parte de la obra de otro salvadoreño: Rafael Menjívar Ochoa. En novelas como Los años marchitos (1990, escrita en los últimos años de la guerra salvadoreña que termina en 1992 y desde su exilio mexicano, del que regresa solo en 1999) y Cualquier forma de morir, publicada en cambio en 2006, se encuentran pautas de la locura del discurso relacionada con el desastre. En la primera, Los años marchitos, el narrador-protagonista es un actor de radionovela que, por falta de trabajo, decide aceptar una "oferta" de la policía. Tiene que dar su voz a la falsa confesión de un guerrillero, quien va a cargarse todas las acusaciones sobre el secuestro y asesinato de un político importante. Por consiguiente, las herramientas literarias de la novela siguen las pautas sintácticas del género negro, por la investigación alrededor de las reales intenciones del Estado, y del thriller, por la hipertrofia del suspense. Ambas modalidades policíacas se interconectan en forma sinérgica para reforzar las potencialidades narrativas de la novela: por un lado, la investigación exhibe la creación artificial de una verdad (horrible y obscena); por otro, el thriller confiere a esta "realidad" una dimensión intrínseca de agobio o, en palabras de Ricardo Piglia, genera la sensación de que "la amenaza forma parte del paisaje y define el espacio" (Piglia, 1979: 13). Es fácil entender que el narrador se encuentra en un contubernio sin salida. El panóptico foucaultiano de Vigilar y castigar se amplía a la vida cotidiana. El filósofo francés nos explica que el instrumento ideado por Jeremy Bentham no se limita a la vigilancia del espacio de la prisión, sino que se constituye cual metáfora del control en todos los contextos del capitalismo; Foucault especifica ahí el dispositivo alrededor del cual se definen los instrumentos y las formas de intervención del control en los hospitales, las fábricas, las escuelas y, por supuesto, las cárceles (Foucault, 2004: 224). 
El conocimiento por parte del Estado de los detalles de la vida privada del protagonista lo obliga a participar en la narrativización (o en la falsificación) de la realidad que el establismbment está armando. Esta posición liminar entre un criterio de verdad (lo más) ontológico posible y otro completamente artificial representa el desmoronamiento de la lógica escritural: "Mi mundo lógico comenzaba a irse al demonio. O el tipo estaba loco [...], o yo era un verdadero imbécil" (Menjívar Ochoa, 1990: 75). Claro, las posibilidades de mantener una actitud de confrontación racional con la realidad hacen oscilar al narrador entre estas, la incredulidad y el miedo a la locura. No estamos frente a una escritura vedada por las amenazas del Estado, sino frente a la construcción de una teatralización de la realidad. La escritura del desastre, por lo tanto, es la falsificación misma, la reiteración de la catástrofe social que el aparato político e institucional respalda.

La misma idea es detectable también en Cualquier forma de morir. La novela presenta una ficcionalización del panóptico foucaultiano ya que las andanzas del narrador-protagonista y los demás actantes se desprenden a partir de una cárcel de la cual pueden salir según las necesidades criminales de los narcotraficantes y del Estado. Cualquier forma de morir es una novela sobre la persecución y la violencia, construida alrededor de esa metáfora foucaultiana. La organización de la vigilancia propia de la cárcel se diluye al espacio exterior a la misma, sin que haya diferencias apreciables entre las dos dimensiones. La realidad circundante es la mera extensión de la cárcel.

La narrativización paranoica del control social, en última instancia, es la imposibilidad de construir una versión positiva de la realidad. Ésta es la idea fundamental -según nuestro punto de vista- que encontramos también casi en la totalidad de la obra de Horacio Castellanos Moya. Podemos señalar, por ejemplo, los cuentos "El asco" y "Con la congoja de la pasada tormenta" (reunidos en 1997 en el volumen El asco. Thomas Bernhard en El Salvador) o la novela El sueño del retorno (2013).

Para tratar de ofrecer una síntesis de esta relación entre escritura paranoica y desorden de las representaciones, nos fijaremos en Insensatez (2005 [2004]). La novela, al empujar la imposibilidad del testimonio (o de su falsificación) hasta dimensiones neuróticas, responde muy bien a los interrogantes que se nos presentan al considerar la escritura del desastre como tentativa (imposible) de racionalización social del mismo. La historia de Insensatez es, desde este punto de vista, paradigmática. El narrador es un escritor huido (presumimos) de El Salvador por unas opiniones contundentes y negativas sobre el presidente de su país. Es contratado para revisar las 1100 cuartillas del informe sobre los crímenes perpetrados 
en los años de la guerra civil. ${ }^{9}$ En la novela se articulan dos cuestiones fundamentales. La revisión del informe se relaciona directamente con la "escritura del desastre" de la guerra, mientras que el contexto cotidiano es la persistencia de la dimensión psíquica de la catástrofe social.

Texto y contexto se condicionan mutuamente en un abismo paranoico que impide la recuperación misma de la memoria. Simple y llanamente, la nuda vida del narrador se constituye como una falta de solución de continuidad con el contexto de violencia antecedente. Esa idea imposibilita de facto el trabajo de recuperación de la memoria. "Yo no estoy completo de la mente, decía la frase que subrayé con el marcador amarillo, y que hasta pasé en limpio en mi libreta personal. [...] Yo no estoy completo de la mente, me repetí, impactado por el grado de perturbación mental en el que había sido hundido ese indígena cachiquel testigo del asesinato de su familia" (Castellanos Moya, 2005: 13). El narrador choca con la supuesta peligrosidad implícita en la indagación de la desaforada violencia que ensangrentó el país. Si al comienzo atribuye la pérdida de las facultades psíquicas a quien vivió el conflicto, en pocas líneas de monólogo la vivencia del desastre llega hasta su presente:

[...] luego de darme cuenta de que me encontraba tan incompleto de la mente que había aceptado y estaba iniciando un trabajo con los curas que ya me habrían puesto en la mira de los militares de este país, como si yo no tuviera ya suficientes problemas con los militares de mi país [...]. De súbito me sentí [...] víctima de una conspiración entre curas y militares en tierra ajena [...]. (Castellanos Moya, 2005: 16-17)

La novela se desenvuelve según el hilo de la representación hipotética a la que le falta una "gran narración" para construir una visión propositiva de la realidad. El sujeto se ve imposibilitado para salir de un vacío semántico, o de una realidad sobreentendida, ${ }^{10}$ ya que no tiene herramientas ideológicas para hacerlo. El desastre no es lo ocurrido, sino la exhibición narrativa de su vivencia.

El desastre inexperimentado, lo sustraído a cualquier posibilidad de experiencia -límite de la escritura. Es menester repetirlo: el desastre des-escribe. Ello no significa que el desastre [...], esté fuera de la escritura, fuera del texto. (Blanchot, 1990: 14)

\footnotetext{
${ }^{9}$ Suponemos que está en Guatemala porque el narrador trabaja en el Arzobispado que, en la realidad histórica del país latinoamericano, comisionó el informe R.E.M.Hi. -Recuperación de la Memoria Histórica- sobre los crímenes de los militares y de la guerrilla.

${ }^{10}$ Como escribe Juan José Saer en "Literatura y crisis argentina", "nunca es más férreo un diktat de cuando es sobreentendido; las órdenes tácitas se infiltran en los actos de los particulares y los modelan desde el interior dándole una apariencia falsamente necesaria” (Saer, 1998: 101).
} 
El desastre es el texto y, en particular, la polifacética relación del protagonista con las fuerzas ocultas (reales o hipotéticas) del Estado; es una escritura investigativa, al mismo tiempo coherente y neurótica, que representa la soberanía como un aparato únicamente conspirativo contra sus ciudadanos. Así, el sufrimiento intelectual vale más que el físico: un sujeto aplastado por la presión del contubernio estatal y sin representaciones propias de la realidad es un individuo incompleto (o no completo) de la mente: "el infierno es la mente y no la carne" (Castellanos Moya, 2005: 83).

Por lo que atañe la relación con los precursores y en particular con el Boom de la literatura hispanoamericana, hemos visto que solo un par de novelas de Franz Galich (Huracán... y Tikal...) retoman la voluntad estética e ideológica de la mayor y más conocida producción que comenzó en el continente a partir de los años sesenta. En Insensatez, notamos la voluntad del efebo de liberarse de los vínculos del pasado literario. El narrador fantasea con sus lecturas e imagina el proyecto de un registrador civil de escribir post-mortem el relato de sus penas: "[...] y a partir de ese golpe el alma en pena del registrador civil contaría su historia, en todo momento con las palmas de sus manos sin dedos apretando las dos mitades de su cabeza para mantener los sesos en su sitio, que el realismo mágico no me es por completo ajeno" (Castellanos Moya, 2005: 73). En nuestra opinión la mímesis del realismo mágico produce, en Castellanos Moya, una referencia iconoclasta de la generación anterior y, al mismo tiempo, la dramatización desesperada de la violencia. En Entre Paréntesis Roberto Bolaño vuelve sobre esta característica del escritor salvadoreño (que es muy común en unos cuantos escritores latinoamericanos que quieren desvincularse de etiquetas). Comentando un pasaje de la obra de Castellanos Moya, Bolaño escribe: "Esta frase suena a realismo mágico. Sin embargo no hay nada mágico en sus libros, salvo tal vez su voluntad de estilo" (Bolaño, 2005: 173).

\section{Conclusión}

Hemos visto como la encrucijada histórica en la cual se encuentran las naciones centroamericanas ya envueltas en las diferentes guerras civiles, requiere un esfuerzo notable para encontrar las coordenadas literarias aptas para la reconstrucción del pasado traumático. Las opciones mayores de esta búsqueda tienen que ver (en el sentido de reproducción o ruptura) con la tradición reciente de la cultura hispanoamericana: una parte de la producción de Franz Galich es continuadora de la experiencia literaria del realismo mágico, característica del conocido boom de la literatura; por otro, en el mismo Galich, en Rey Rosa y en Castellanos Moya detectamos la voluntad de producir un discurso desvinculado de los precursores -a veces en 
polémica con ellos- y caracterizado por una idea estética diferente. En nuestra opinión, esta lucha por liberarse de los patrones ideológicos que las formas estéticas del boom llevaban consigo demuestra una voluntad dúplice, o sea la de buscar la identidad lingüística, literaria y cultural latinoamericana en un espacio de referencias y signos diferentes, y la de dar a conocer las sociedades víctimas de los oprobios bélicos como heterogéneas y no relacionadas masivamente a una concepción ideológica.

La lejanía con una fe política es la que determina, en fin, la escritura del desastre y, añadimos, una visión menos formal y más problemática de las estructuras semánticas que el desastre mismo pone en marcha. Por esto, la peculiaridad de (sobre todo) Rey Rosa y Castellanos Moya es la de representar una sociedad desmoronada, afectada en la capacidad de producir representaciones (pro)positivas del presente y aniquilada en la voluntad de dar forma lógica a los acontecimientos criminales u ocultos. Una escritura paranoica en la que el entorno social está constituido por una serie de conexiones lógicas que no encuentra cabida en una estructura semántica coherente.

Revisado por José Morales

\section{Referencias bibliográficas}

Agamben, Giorgio (1995), Homo sacer. Il potere sovrano e la nuda vita. Torino: Einaudi.

Ballinger, Pamela (1998), "The Culture of Survivors: Post-Traumatic Stress Disorder and Traumatic Memory", History and Memory, 10(1), 99-132.

Blanchot, Maurice (1990), La escritura del desastre. Caracas: Monte Ávila.

Bolaño, Roberto (2005), Entre paréntesis. Barcelona: Anagrama.

Bolognese, Chiara (2009), Pistas de un naufragio. Una cartografía de Roberto Bolaño. Madrid: Al Margen.

Castellanos Moya, Horacio (2001), El arma en el hombre. Barcelona: Tusquets.

Castellanos Moya, Horacio (2005), Insensatez. Barcelona: Tusquets [ed. orig.: 2004].

Castellanos Moya, Horacio (2007), El asco. Thomas Bernhard en El Salvador. Barcelona: Tusquets [ed. orig.: 1997].

Castellanos Moya, Horacio (2013), El sueño del retorno. Barcelona: Tusquets.

Cortez, Beatriz (2009), Estética del cinismo. Pasión y desencanto en la literatura centro-americana de posguerra. Guatemala: F\&G.

Foucault, Michel (2004), Sorvegliare e punire. Nascita della prigione. Torino: Einaudi. Fresán, Rodrigo (2008), "El samurai romántico", in Edmundo Paz Soldán; Gustavo Faverón Patrau (comps.), Bolaño salvaje. Barcelona: Candaya, 313-323.

Galich, Franz (1995), Huracán corazón del cielo. Managua: Anamá. 
Galich, Franz (2000), Managua Salsa City ¡Devórame otra vez! Panamá: Géminis.

Galich, Franz (2006), Y te diré quien eres (Mariposa traicionera). Managua: Anamá.

Galich, Franz (2012), Tikal Futura. Memorias para un futuro incierto. Guatemala: F\&G.

Lezama Lima, José (2009), Paradiso. La Habana: Letras cubanas.

Menjívar Ochoa, Rafael (1990), Los años marchitos. Madrid: Istmo.

Menjívar Ochoa, Rafael (2006), Cualquier forma de morir. Guatemala: F\&G.

Piglia, Ricardo (comp.) (1979), Cuentos de la serie negra. Buenos Aires: CEAL.

Piglia, Ricardo (1991), "La ficción paranoica”, diario Clarín, 05 de mayo, pp. 4-5.

Rey Rosa, Rodrigo (2009), El material bumano. Barcelona: Anagrama.

Rey Rosa, Rodrigo (2013), Imitación de Guatemala. México: Alfaguara.

Ribeiro, António Sousa (2008), "Cartografias do não-espaço: Viagem ao fim do mundo na literatura do Holocausto”, Revista Crítica de Ciências Sociais, 83, 5-18.

Saer, Juan José (1998), El concepto de ficción. Buenos Aires: Espasa Calpe/Ariel.

Artigo recebido a 18.12.2014

Aprovado para publicação a 30.11.2015

\section{Andrea Pezzè}

Centro de Estudos Sociais da Universidade de Coimbra

Colégio de São Jerónimo, Largo D. Dinis, Apartado 3087, $3000-995$ Coimbra, Portugal

Contacto: andreapezze@ces.uc.pt

\section{The Disaster in Contemporary Central American Literature}

This article aims to analyze examples of Central American literary representations about the ravages of the latest civil wars. This goal will be achieved by studying three essential writers from this region: Horacio Castellanos Moya from El Salvador, Rodrigo Rey Rosa from Guatemala, and Franz Galich from both Guatemala and Nicaragua. These writers' countries are now in the process of translating their traumatic experiences into a coherent linguistic structure. The theoretical underpinnings are drawn from Maurice Blanchot's essay L'écriture du

\section{Le désastre dans la littérature de l'Amérique centrale contemporaine}

Cet article se propose d'analyser quelques exemples de formulations littéraires de l'Amérique centrale portant sur les dommages causés par les dernières guerres civiles. Pour atteindre cet objectif, nous nous pencherons tout particulièrement sur trois écrivains incontournables en la matière: Horacio Castellanos Moya de l'El Salvador, Rodrigo Rey Rosa du Guatemala et Franz Galich entre Guatemala et Nicaragua, pays qui, à l'heure actuelle, cherchent à traduire leurs expériences traumatiques en un système linguistique cohérent. Nos réflexions reposent sur 
désastre (1980) as well as from studies about semantic memory and theories about social blame. The objective is to demonstrate that Central American literature in particular and Spanish-American culture in general are at a new crossroads in their style of representation of their social fabrics.

Keywords: Central America; guerrilla; literature; memory; testimony. l'essai de Maurice Blachot L'écriture du désastre (1980), les études sur la sémantique de la mémoire et les théories sur les responsabilités sociales pour démontrer que la littérature de l'Amérique centrale - et, plus généralement, la littérature hispano-américaine - se trouvent à un nouveau carrefour du style de représentation de la réalité sociale.

Mots-clés: Amérique centrale; guérilla; littérature; mémoire; témoignage. 